\title{
Evaluation of Municipal Fitness Programs for Women with Low Back Pain
}

\author{
John Kosmas ${ }^{1}$, Yannis Georgiou², Eleni Marmara², Aggeliki Fotiou ${ }^{3}$ \\ ${ }^{1}$ Harokopio University of Athens, Department of Informatics and Telematics, Athens, Greece, ${ }^{2}$ National \& Kapodistrian University of Athens, School \\ of Physical Education \& Sport Science, Athens, Greece, ${ }^{3}$ Hellenic Open University, Business Administration, Patras, Greece
}

\begin{abstract}
The present study examines the impact among several factors and the Lower Back Pain (LBP) in 131 women, participating in municipal physical activity programs who declared LBP. The purpose was to investigate the effect of municipal sports programs in female's participants LBP intensity. Data from 131 LBP sufferer women collected in the beginning and after a six months period. Municipal physical activity programs did not affect negatively LBP. Specific features participants (mothers) present greater risk in future to appear LBP. Municipal physical activity programs reduce the felling of LBP in women without children.

Key words: Physical Activity, Pain, Movement Restriction, Health
\end{abstract}

\section{Introduction}

In 2000, a European Community working group met with the phenomenon of acute undetected pain in the lumbar spine. Experts from almost all countries in the European zone took place in this meeting, to identify potential harmful factors, to establish a framework for prevention and to formulate guidelines for the treatment of LBP among the field's professionals. In the results, the working group made widely known the poor association of the LBP feeling in connection to the radiographic diagnosis, as it often did not coincide with the pain in the particular area of the patient. It also included guidelines for exercise as a mean of preventing and of reducing LBP during its chronic phase. Advices were also given on what kind and at which intensity of exercise is appropriate.

LBP defined as the pain followed by concomitant discomfort, located between the lateral and the lower gluteus folds (Haryono, Kawilarang, \& Prastowo, 2019). Acute LBP defined as the one lasts less than 6 weeks, sub acute the one between 6-12 weeks, while for more than 12 weeks characterized as chronic. Pain divided in two categories according to the causal risk factors. Red-flag sign defined the group who has predisposing factors to experience LBP. This category includes ages under 25 and over 55 years, recent history of violent trauma, steadily worsening non-mechanical pain (not receding with bedtime), chest pain, malignant tumor medical history, prolonged use cortisone, unexplained weight loss, and various other factors of minor importance (Waddell, Feder, McIntosh, Lewis, \& Hutchinson, 1998). The yellow-flag sign refers to secondary risk factors for LBP. Participants according to their working group stated that, work satisfaction, emotional issues (stress, depression, etc.), pain management, and low levels of exercise are factors that cause chronic LBP (Kendall, Linton, \& Main, 1997).

The cost of any form of LBP evaluated as GDP percentage. In Finland, the total cost reaches 0.8\% (Heikki, 2002), in the Netherlands 1.7\% (Van Tulder, Koes, \& Bouter, 1995), in Sweden $1.7 \%$ (Nachemson, 1991), in the United States is $2.2 \%$ (Frymoyer \& Cats-Baril, 1991) of the GDP's of each country. UK has the highest numbers of back pain related absenteeism in the EU, nearly 10 million workdays were lost to back pain in 2014, (Miller, 2014), where the cost also reaches $2 \%$ of GDP (Maniadakis \& Gray, 2000), agreed with survey results presented shown that $75-85 \%$ of absenteeism were due to back pain (Andersson, 1999; Waddell et al., 1998). Artur (2014), underline that LBP is the leading cause of disability for most of countries in Europe, North Africa and a part of Latin America. The majority of researches have so far not addressed LBP issues

\section{Correspondence:}

\section{Montenegro}

Gport

\section{J. Kosmas}

Harokopio University of Athens, Department of Informatics and Telematics, 25-27, Peramou street, Ampelokipoi, 11522, Athens, Greece

E-mail: johndopapkosmas@gmail.com 
in municipal sports programs, except one research which dealt with this kind of issues (Kosmas, Marmara, \& Stergioulas, 2008).

The risk factors for back pain emerged through surveys are, age (Bailey, 2009), body mass index (Heliövaara, 1989), and childbirth (Bailey, 2009). There is a clash about smoking as a risk factor for LBP. Some studies have shown LBP is associated with cigarette smoking (Heliövaara, Mäkelä, Knekt, Impivaara, \& Aromaa, 1991; Liira, Shannon, Chambers, \& Haines, 1996), while others have not shown a relationship (Smedly, Egger, Cooper \& Coggon, 1995; Leboeuf-Yde, Kyvik, \& Bruun, 1998).

Four factors were used establishing four research hypotheses as the base of the research. A) Body Mass Index (BMI). The higher the BMI the highest the LBP intensity (Spyropoulos et al., 2007). B) Childbirth. LBP intensity in women with childbirth is higher than those who have not (Bailey, 2009). C) Smoking. There is a connection of Smoking factor and LBP and D) Metabolic Equivalent (MET). Too high or too low physical activity levels deteriorate LBP (Lallukka et al., 2017). The purpose of this study was to outline the profile of the women participating in municipality sports programs, suffering from LBP. Based upon the profile and in relation with the independent variables, new guidelines for renewed physical activity municipality programmes could be created concerning the special needs of the population, contributing in better health and fitness results of the participants, and acting as factors for avoiding and reducing the risk of LBP evolvement.

\section{Methods}

Since January 2009, female Municipality Sports Programs participants from the municipalities of the region of Attica, Greece, asked to fill in a pen and pencil questionnaire with three parts; first the demographic questionnaire, second the
LBP severity questionnaire and third the activity evaluation in METs questionnaire. There was a written consent for their participation. The selection of the Municipalities based on the separation of the Prefecture of Athens into four (4) regional areas: central, eastern, southern and western (Athens Prefecture, 2008). Four (4) Municipalities selected from each regional sector. In each area, the most populated municipality, the less populated and two municipalities with random sampling selected for the survey (Thomas \& Nelson, 2003). From the 635 fully answered and returned questionnaires, only 131 (20.7\%) declared their LBP suffering and only these selected as participants. To assess the intensity of pain and the effect of the variables, descriptive statistics, $t$ tests for independent samples and ANOVA independent sample carried out.

The mean values of the responses of the participants (dependent variables) compared with the independent variables (age, smoking, educational level, etc.). Data were analyzed using SPSS version 17.0 statistical software for Windows (SPSS, Inc., Chicago, IL, USA). The results presented as means $(\mathrm{M})$ and Standard Deviations (SD), or as percentages. For continuous variables, the significance of the differences between the groups analyzed using one-way analysis of variance followed by post hoc comparisons within dependent samples t-test, and for categorical variables using Tukey criterion.

In a sample of 635 women, $131(20.7 \%)$ reported LBP. The average age of women participating was at $\mathrm{M}=51 \pm 12.12 \mathrm{ye}$ ars (Table 1). This means that the average age of participation in the municipal programs is about fifty-one years $(M=51)$, (S.D. $=12.11$ ) with an age range from $\min =17$ to $\max =67$ years. Our research, however, focused on those with LBP. Only the 131 participants declared LBP to investigate the demographic and habitual independent variables.

Table 1. The somatometric and demographic characteristics (mean values standard deviations) of the participants in the present study $(n=131)$

\begin{tabular}{ccc}
\hline & $\mathbf{M}(\mathbf{n})=\mathbf{1 3 1}$ & S.D. \\
\hline Age & 41 & 1.10 \\
Weight $(\mathrm{kg})$ & 70.61 & 0.71 \\
Height $(\mathrm{m})$ & 1.67 & 0.005 \\
BMI $\left(\mathrm{kg} / \mathrm{m}^{2}\right)$ & 25.31 & 3.44 \\
\hline
\end{tabular}

Body weight of participants $(\mathrm{N}=131)$, was $70 \mathrm{~kg}(\mathrm{M}=70.61$ $\pm 0.71 \mathrm{kgr})(\mathrm{min}=47-\max =97)$, while their height $1.67 \mathrm{~m}(\mathrm{M}$ $=1.67 \mathrm{~m} \pm 0.005)(\min =1.50-\max =1.84)$. A percentage of $81.7 \%$ of the values are concentrated in the area of $1.50-1.71 \mathrm{~m}$. These variables combined provide the Body Mass Index (BMI).

Since January 2009, female Municipality Sports Programs participants from the municipalities of the region of Attica, Greece, asked to fill in a pen and pencil questionnaire with three parts; first the demographic questionnaire, second the LBP severity questionnaire and third the activity evaluation in METs questionnaire. There was a written consent for their participation.

LBP severity evaluated with the 'Grading the severity of chronic pain' questionnaire (Von Korff, Ormel, Keefe, \& Dworkin, 1992). The questionnaire consists of eight questions (Q). Q1 How would you rate six months before your pain in the middle on a scale from 0 to 10 where $0=$ no pain and $10=$ the worst possible pain, q2 How would you currently rate your pain in the middle on a scale from 0 to 10 where $0=$ no pain and $10=$ the worst possible pain?, q3 In the last six months, how intense was the worst back pain you felt on a scale from 0 to 10 where $0=$ no pain and $10=$ the worst possible pain?, q4 In the last six months, and on average, how severe was the waist pain you felt on a scale from 0 to 10 where $0=$ no pain and $10=$ the worst possible pain, q5 For how many days, in the last six months, have you abstained from your usual activities (work, school, home, sports) because of back pain? Abstinence days, q6 In the last six months, how has the pain acted in the middle of your everyday activities on a scale from 0 to 10 where $0=$ no effect and $10=$ impossible to do any activity?, q7 In the last six months how has your ability to participate in creative / social / family activities changed due to pain in the middle on a scale from 0 to 10 where $0=$ no change and $10=$ tremendous change?, and $q 8$ In the last six months, how much pain has in the middle of your ability to work (including homework) on a scale of 0 to 10 where 0 $=$ no change and $10=$ huge change? . Participants report some observations they made about pain. For each observation they put a circle in a number from 0 to 6 to indicate whether their 
physical activities such as crouching, weight lifting, walking, driving, sports affect or could affect their LBP at this time (0: absolutely disagree, 6: absolutely agree). For the evaluation of the activity of each participant in METs we used the questionnaire of Kriska and Caspersen (1997), which has been translated in Greek language in 2011 (Marmara, Papacharalambous, Kouloulias, Maridaki, \& Baltopoulos, 2011). Physical exercise indices are expressed as energy expenditure variables per day or per week, and are usually given as calories per day (kcal / day) or as metabolic equivalents per day (MET / day). In various studies, physical activity is often categorized according to its type and intensity. Physical exercise habits are measured in the form of frequency and duration of physical activity. The types of physical exercise used in most studies include physical activity during working, leisure time, home routine, family care, etc. The intensity of physical activity represents the metabolic cost required to carry out the effort. Often effort is measured in MET units. A MET is the metabolic cost corresponding to the basal metabolism and equates to $4,184 \mathrm{~kJ} / \mathrm{kg} / \mathrm{h}$, the energy spent in the sitting position or else with $3.5 \mathrm{ml}$ of oxygen consumed per kg of body mass per minute, which is about $1 \mathrm{kcal} / \mathrm{kg} / \mathrm{h}$.

\section{Results}

The BMI groups defined as $<25$ for normal body weight, = 25-30 for overweight, and $>30$ for obese (Mimic, Vuki- cevic, \& Vujacic, 2019). BMI's results show that most of the participants are within the limits of normal body weight. The average $(M=25.2)$ is slightly above the woman's normal body weight limit $(\min =18 \& \max =35)$ and $30 \%$ has exceeded the accepted value $[(\mathrm{Q} 5) \mathrm{F}(2.128)=3.1, \mathrm{p}<0.05, \mathrm{~F}(2.128)=$ $3.93, \mathrm{p}<0.05, \mathrm{~F}(2)(2,128)=5.87, \mathrm{p}<0.05, \mathrm{~F}(2.128)=3.09$, $\mathrm{p}<0.05$ respectively]. For the rest of the questions no statistically significant differences observed ( $\mathrm{p}<0.05$, see Table 2 ).

Tukey post hoc analyzes for statistically significant differences showed that for Question 12c "In the last six months, how intense the worst LBP that you have felt", 25-30 group $(\mathrm{M}=3.63 \pm 0.91)$ had a statistically significant difference with those who had MM. $31<(\mathrm{M}=2.9 \pm 0.55)$ on pain intensity in the last six months. For Question $12 \mathrm{f}$ "In the last six months, how much pain has affected the LBP in your dayto-day activities" $0.31<(\mathrm{M}=3.64 \pm 1.53)$ had a statistically significant difference with those who had MM. 25-30 ( $\mathrm{M}=$ $4.81 \pm 1.63)$ and $0-24(\mathrm{M}=4.65 \pm 1.40)$ on the effect of pain in the last six months on daily activities. For Question 4 (Q4) "I should not do activities that could aggravate my pain", 0-24 $(\mathrm{M}=5.32 \pm 1.54)$ there was a statistical difference with those having MM. $31<(M=4 \pm 1.69)$ for activities that could exacerbate pain.

While for Question 5 (Q5) "I cannot do activities that would make my pain stronger", there were no statistically significant differences between women of different BMIs.

Table 2. Descriptive table ANOVA BMI $p<0.05$

\begin{tabular}{|c|c|c|c|c|c|c|}
\hline Question & & Sum Square & df & Mean Square & $\mathbf{F}$ & $\mathbf{p}$ \\
\hline \multirow[t]{3}{*}{ que12a } & Groups & 1.554 & 2 & .777 & .543 & .582 \\
\hline & Error & 183.179 & 128 & 1.431 & & \\
\hline & Total & 184.733 & 130 & & & \\
\hline \multirow[t]{3}{*}{ que $12 \beta$} & Groups & 4.164 & 2 & 2.082 & 1.257 & .288 \\
\hline & Error & 212.065 & 128 & 1.657 & & \\
\hline & Total & 216.229 & 130 & & & \\
\hline \multirow[t]{3}{*}{ que12c } & Groups & 6.594 & 2 & 3.297 & 3.100 & $.048^{*}$ \\
\hline & Error & 136.109 & 128 & 1.063 & & \\
\hline & Total & 142.702 & 130 & & & \\
\hline \multirow[t]{3}{*}{ que12d } & Groups & 2,368 & 2 & 1,184 & 1,078 & .343 \\
\hline & Error & 140,548 & 128 & 1,098 & & \\
\hline & Total & 142,916 & 130 & & & \\
\hline \multirow[t]{3}{*}{ que12e } & Groups & 2.882 & 2 & 1.441 & .391 & .677 \\
\hline & Error & 472.035 & 128 & 3.688 & & \\
\hline & Total & 474.916 & 130 & & & \\
\hline \multirow[t]{3}{*}{ que12f } & Groups & 17.709 & 2 & 8.855 & 3.933 & $.022^{*}$ \\
\hline & Error & 288.199 & 128 & 2.252 & & \\
\hline & Total & 305.908 & 130 & & & \\
\hline \multirow[t]{3}{*}{ que12g } & Groups & 5.196 & 2 & 2.598 & 1.858 & .160 \\
\hline & Error & 178.972 & 128 & 1.398 & & \\
\hline & Total & 184.168 & 130 & & & \\
\hline \multirow[t]{3}{*}{ que12h } & Groups & 5.641 & 2 & 2.820 & 1.794 & .170 \\
\hline & Error & 201.260 & 128 & 1.572 & & \\
\hline & Total & 206.901 & 130 & & & \\
\hline \multirow[t]{3}{*}{ Q1 } & Groups & 13.579 & 2 & 6.789 & 2.512 & .085 \\
\hline & Error & 345.963 & 128 & 2.703 & & \\
\hline & Total & 359.542 & 130 & & & \\
\hline $\mathrm{Q} 2$ & Groups & 1.244 & 2 & .622 & .327 & .721 \\
\hline
\end{tabular}


(continued from previous page)

\begin{tabular}{|c|c|c|c|c|c|c|}
\hline Question & & Sum Square & df & Mean Square & $\mathbf{F}$ & $\mathbf{p}$ \\
\hline & Error & 243.305 & 128 & 1.901 & & \\
\hline & Total & 244.550 & 130 & & & \\
\hline \multirow[t]{3}{*}{ Q3 } & Groups & .419 & 2 & .210 & .089 & .915 \\
\hline & Error & 300.375 & 128 & 2.347 & & \\
\hline & Total & 300.794 & 130 & & & \\
\hline \multirow[t]{3}{*}{ Q4 } & Groups & 27.555 & 2 & 13.778 & 5.875 & $.004^{*}$ \\
\hline & Error & 300.170 & 128 & 2.345 & & \\
\hline & Total & 327.725 & 130 & & & \\
\hline \multirow[t]{3}{*}{ Q5 } & Groups & 19.468 & 2 & 9.734 & 3.093 & $.049^{*}$ \\
\hline & Error & 402.777 & 128 & 3.147 & & \\
\hline & Total & 422.244 & 130 & & & \\
\hline \multirow[t]{3}{*}{ Q6 } & Groups & 10.556 & 2 & 5.278 & 2.487 & .087 \\
\hline & Error & 271.688 & 128 & 2.123 & & \\
\hline & Total & 282.244 & 130 & & & \\
\hline
\end{tabular}

The percentage of the participants who had given childbirth Primary Sports Programs where they are highly opposed to thowas $75.6 \%$, and of those without childbirth were $24.4 \%$ (Table 3). se without children. For this categorical variable (as for smoking This is indicative of the participation of women with children in variable) $t$ tests for independent samples performed.

Table 3. The categorical variables (child - smoking - if there is a midwife - if there is a back pain) in absolute numbers and percentages. $(n=131)$.

\begin{tabular}{ccccc}
\hline $\mathbf{n = 1 3 1}$ & NO & \% & YES & $\%$ \\
\hline Children & 32 & 24.4 & 99 & 75.6 \\
Smoking & 95 & 72.5 & 36 & 27.5 \\
Operation & 131 & 100 & 0 & 0 \\
\hline
\end{tabular}

In the control t panel (Table 4) we can observe that in fo- average of LBP within the last six months it was intense for those ur questions (Question 12d, Question 4 (Q4), Question 5 (Q5), Question 6 (Q6)) there are statistically significant differences [ $\mathrm{t}$ (129), $\mathrm{p}<0.05], \mathrm{t}(129)=-2.27, \mathrm{p}<0.05, \mathrm{t}(129)=-3.97, \mathrm{p}<0.05$, $\mathrm{t}(129)=-2.29, \mathrm{p}<0.05$, respectively. For the remaining questions, no statistically significant differences $(\mathrm{p}<0.05$, see Table 4) observed. The above statistical check implies that the highest who had children compared with those who did not have (Question $12 \mathrm{~d}$ ). At the same time, childless participants seem to be more determined to engage in activities that would exacerbate their pain (Question Q4, Question Q5), and they think that sport reduced LBP. (Question Q6).

Table 4. Mean values, standard deviations, control t and statistical significance in women with children (N1 = 131) and without children (N2 = 504) in questions $p<0.05$

\begin{tabular}{ccccc}
\hline Question & Children & No Children & t test & Sign. \\
\hline que12a & $3.51 \pm 1.11$ & $3.50 \pm 1.41$ & 0.062 & 0.950 \\
que12b & $3.64 \pm 1.10$ & $4.31 \pm 1.67$ & -2.595 & 0.011 \\
que12c & $3.55 \pm 1.00$ & $3.40 \pm 1.18$ & 0.699 & 0.486 \\
que12d & $3.79 \pm .89$ & $3.06 \pm 1.29$ & 3.605 & $0.000^{*}$ \\
que12e & $3.68 \pm 1.87$ & $3.40 \pm 2.02$ & 0.721 & 0.472 \\
que12f & $4.66 \pm 1.45$ & $4.31 \pm 1.74$ & 1.137 & 0.258 \\
que12g & $2.79 \pm 1.17$ & $2.34 \pm 1.18$ & 1.895 & 0.60 \\
que12h & $3.95 \pm 1.27$ & $3.75 \pm 1.21$ & 0.816 & 0.416 \\
Q1 & $4.79 \pm 1.57$ & $4.21 \pm 1.86$ & 1.726 & 0.087 \\
Q2 & $3.66 \pm 1.28$ & $3.87 \pm 1.62$ & -0.746 & 0.457 \\
Q3 & $4.12 \pm 1.43$ & $4.15 \pm 1.79$ & -0.113 & 0.910 \\
Q4 & $4.77 \pm 1.51$ & $5.50 \pm 1.70$ & -2.272 & $0.025^{*}$ \\
Q5 & $3.80 \pm 1.68$ & $5.18 \pm 1.78$ & -3.972 & $0.000^{*}$ \\
Q6 & $3.97 \pm 1.52$ & $4.65 \pm 1.18$ & -2.294 & $0.023^{*}$ \\
\hline
\end{tabular}

The majority of the participants do not smoke (72.5\%) (Table 5). This evidences the hypothesis that those who are doing sport in a regular basis usually do not smoke. In the control t panel (Table 5), no statistically significant differences found between smokers and non-smokers. A finding that shows that smoking does not differentiate the responses of the participants in the PMS programs for the LBP. 
Table 5. Mean values, standard deviations, control t and statistical significance in smokers $(\mathrm{N} 1=36)$ and non-smokers $(\mathrm{N} 2=95)$ in questions

\begin{tabular}{ccccc}
\hline Question & Smokers & Non Smokers & t test & Sign. \\
\hline que12a & $3.53 \pm 1.44$ & $3.51 \pm 1.09$ & 0.96 & 0.924 \\
que12b & $3.69 \pm 1.19$ & $3.85 \pm 1.42$ & -0.625 & 0.533 \\
que12c & $3.50 \pm 1.23$ & $3.52 \pm 0.97$ & -.0 .128 & 0.898 \\
que12d & $3.52 \pm 1.10$ & $3.65 \pm 1.02$ & -0.607 & 0.545 \\
que12e & $3.72 \pm 1.92$ & $3.57 \pm 1.91$ & 0.382 & 0.703 \\
que12f & $4.47 \pm 1.57$ & $4.62 \pm 1.52$ & -0.494 & 0.622 \\
que12g & $2.80 \pm 1.28$ & $2.64 \pm 1.15$ & 0.7 & 0.485 \\
que12h & $4.11 \pm 1.30$ & $3.83 \pm 1.24$ & 1.133 & 0.259 \\
Q1 & $4.50 \pm 1.78$ & $4.71 \pm 1.62$ & -0.662 & 0.509 \\
Q2 & $3.61 \pm 1.53$ & $3.75 \pm 1.31$ & -0.545 & 0.586 \\
Q3 & $3.86 \pm 1.65$ & $4.23 \pm 1.46$ & -1.247 & 0.215 \\
Q4 & $4.97 \pm 1.66$ & $4.94 \pm 1.56$ & 0.080 & 0.937 \\
Q5 & $4.19 \pm 1.78$ & $4.12 \pm 1.81$ & 0.192 & 0.848 \\
Q6 & $4.19 \pm 1.45$ & $4.12 \pm 1.48$ & 0.235 & 0.814 \\
\hline
\end{tabular}

Metabolism defined as the metabolic cost corresponding to the basic metabolism and considered as the energy spent in a seated sedentary position. It equals $1.0(4.184 \mathrm{~kJ}) / \mathrm{kgr} / \mathrm{h}$, or else with $3.5 \mathrm{ml} / \mathrm{kg} / \mathrm{min}$ of oxygen consumed i.e. about $1 \mathrm{kcal}$ / kg / h (Kriska \& Caspersen, 1997). Ainsworth et al., (2000) set the intensity limits for physical activity classification as follows: light $<3$ MET, moderate 3-6 METs, heavy $>6$ MET. Based on these limits and by dividing the METs of the participants, we can highlight some important elements. Table 6, shows a high average of those who have shown LBP $(M=49.62 \pm 0.912)$.

Table 6. The MET of exercising women's pain (mean-type, $\mathrm{n}=131$ )

\begin{tabular}{ccc}
\hline & $\mathbf{M}$ & S.D. \\
\hline MET PAIN & 49.62 & 0.912 \\
\hline
\end{tabular}

Finally the presented results show that women choose the specific programs regardless of their low or high weight.

\section{Discussion}

The aim of the present study focus on the municipal physical activity programs for female participants. The main goals of these programs are to improve fitness and to increase activity levels of female participants, minimizing at the same time the fear of LBP, or the LBP itself, for those suffering of it. This study evaluated the effect of municipality sports programs for women considering sociodemographic and lifestyle factors to the improvement or not of the LBP. Measures of the self-declared replies in the beginning and six months after implementation can also provide useful results of the effect of the municipal sports program to the intensity of the LBP (Le Borgne, Boudoukha, Petit, \& Roquelaure, 2017).

Hypotheses concerning the factors connected to the LBP are supported by data in this research. Variables such as age, Body Mass Index (BMI), Childbirth, Smoking, and too high or too low physical activity by counting the Metabolic Equivalent (MET), demonstrate statistical significance with the appearance and the intensity of LBP. Analyses of the given answers shows a greater effect of pain on participants with BMI between 25-30 \& 0-24 compared to participants with $\mathrm{BMI}>31$. As indicated by the participants belong to these two groups of BMI (25-30 \& 0-24), pain effected more their daily activities, without this intensity exceeding 5 on a scale from $1-10$. Women with BMI 25-30 show more severe pain than those who had higher BMI $(31 \leq)$ during the last six months, while the intensity did not exceed 5 on the above-mentioned scale. Participants with normal BMI (0-24) seemed to be more afraid of exercise at the risk of feeling more intense pain than participants who were obese $(31<)$. Similar surveys' results have shown that the highest the BMI, the more intensive the pain (Björck-van et. al., 2008). LBP seems to be statistically significant higher $(p=0.000)$ in the female group who had been given birth than those who had not. Baily (2009) states that one of the reasons concerns hormonal factors. He considers that specificity of female nature, where changes in hormone levels are continuous, creates an additional risk factor, thus the percentage of women suffering from LBP is significantly higher than this of men. A percentage of $50-60 \%$ of women who gave birth seems to be more likely to suffer from LBP, while those who did not have a pregnancy suffer only at 15\% (Ostgaard, Andersson, \& Karlsson, 1991), confirming our research case.

Another notable finding is that there is no correlation between smoking and LBP. There was no statistical significance in any query but in any common feature of the two groups (smokers-non-smokers). Goldberg, Scott, \& May, (2000), came to the same conclusion as the data obtained had a vague meaning. As reported by Goldberg et al. in the review, there were not enough articles to create a clear and strong correlation between smoking and LBP. Perhaps in our own study the sample was not able to give us the real dimension of the situation. Contrariwise, other studies' results correlate smoking to LBP (Shiri, Karppinen, Leino-Arjas, Solovieva, \& Viikari-Juntura, 2010). The main conclusion of a resent review concerning the correlation between smoking and LBP seems to be positive, especially in adolescents but also in smokers, no matter if they gave up smoking or not (Shiri et al., 2010). Women $(\mathrm{N}=131)$ who reported LBP had almost all a high MET score. Only $3 \%$ of the participants scored less than 25 METs. They respond they participate in a variety of physical activities, while several 
declared that constant intensity prevailed in their daily routine. Mean value is $\mathrm{M}=49.61$ while the intermediate $\mathrm{MO}=45.12$. The difference in variance measures is that there is more than one prevailing price. More than half of those who diagnosed with LBP have between 50 and 64 METs, while about $40 \%$ has less than 50 METs.

An assumption concerning the participants declared LBP could be that the intensity of the activity creates high loads in their spine resulting in strained and manifested pain. Another possibility is that their daily routine activities add them an extra load. Eurobarometer in 2004 published a study carried out in 15 EU Member States (including Greece) in the framework of its actions on health and physical activity. Research aimed to assess the MET/week in each country through personal interviews by all participants. Greece had one of the highest scores in METs/week concerning females participants $(M=35.12)$. The results of the abovementioned research confirm the present study's results since high METs score is their common feature. Under the consideration that Eurobarometer conducted the research in a general population while the present study in physical active female participants, it is easily understandable that weekly loads for women in Greece are such that they cause LBP problems. Mortimer, Pernold, \& Wiktorin (2006) report the direct association of high METs scores with LBP. Similar findings presented in other studies (Mortimer et al., 2001). The common feature of all of these findings is the correlation between METs scores and LBP. Researches' results show, that excesses in activities would have the same effects as inactivity for those who experienced LBP. These views match to Campello, Nordin, \& Weiser (1996) theory of the inverted " $U$ ". These positions and views later agreed by other researchers (Heneweer, Vanhees, \& Picavet, 2009).

Based upon the findings of the research, a good perspective is to include special training programs for pregnant women in their design as part of innovation that will create a more competitive organization in the sports product market (Spais, 2007). Informing young people, through organized workshops, newsletters distribution in schools etc., about the benefits of exercise could be the basis for preventing LBP in young age groups. The marketing department of the municipal sports organization should take initiatives to update the age target group's 17-26 programs, while there is another good opportunity for the organization to create specialized programs focused on women's age target groups. Future research should identify exercise's variables (intensity, type of exercise, etc.) of the program over a period of more than six months, which aim will be the substantially reduce the LBP. This will be in order to prevent the LBP annoying symptom; citizens should enjoy quality and effective services always for their own wellbeing and health.

\section{Acknowledgements}

There are no acknowledgements.

\section{Conflict of Interest}

The authors declare that there are no conflicts of interest.

Received: 1 June 2019 | Accepted: 4 August 2019 | Published: 11 October 2019

\section{References}

Ainsworth, B.E., Haskell, W.L., Whitt, M.C., Irwin, M.L., Swartz, A.M., Strath, S.J., O'Brien, W.L., Bassett Jr, D.R., Schmitz, K.H., Emplaincourt, P.O., Jacobs Jr, D.R., \& Leon, A.S. (2000). Compendium of Physical Activities: an Update of Activity Codes and MET Intensities. Medicine \& Science in Sports \& Exercise, 32(9), S498-S504. doi: 10.1097/00005768-200009001-00009
Andersson, G.B. (1999). Epidemiological features of chronic low-back pain. The Lancet, 354(9178), 581-585. doi: 10.1016/s0140-6736(99)01312-4

Arthur, M. (2014). Institute for Health Metrics and Evaluation. Nursing Standard, 28(42), 32-32. doi: 10.7748/ns.28.42.32.s33

Bailey, A. (2009). Risk factors for low back pain in women: still more questions to be answered. Menopause, 16(1), 3-4. doi: 10.1097/ gme.0b013e31818e10a7

Campello, M., Nordin, M., \& Weiser, S. (1996). Physical exercise and low back pain. Scandinavian journal of medicine \& science in sports, 6(2), 63-72.

Frymoyer, J.W., \& Cats-Baril, W.L. (1991). An overview of the incidences and costs of low back pain. The orthopedic clinics of North America, 22(2), 263-271.

Goldberg, M.S., Scott, S.C., \& Mayo, N.E. (2000). A review of the association between cigarette smoking and the development of nonspecific back pain and related outcomes. Spine, 25(8), 995-1014.

Haryono, I. R., Kawilarang, M., \& Prastowo, N. A. (2019). Leg length discrepancy in college students and its association with low back pain: a preliminary study. Journal of Anthropology of Sport and Physical Education, 3(2), 15-18. doi: 10.26773/jaspe.190403

Heliövaara, M. (1987). Body Height, Obesity, and Risk of Herniated Lumbar Intervertebral Disc. Spine, 12(5), 469-472. doi: 10.1097/00007632198706000-00009

Heliövaara, M., Mäkelä, M., Knekt, P., Impivaara, O., \& Aromaa, A. (1991). Determinants of Sciatica and Low-Back Pain. Spine, 16(6), 608-614. doi: 10.1097/00007632-199106000-00002

Heneweer, H., Vanhees, L., \& Picavet, H.S.J. (2009). Physical activity and low back pain: a U-shaped relation? Pain, 143(1-2), 21-25. doi: 10.1016/j. pain.2008.12.033

Kendall, N.A.S., Linton, S.J., \& Main, C.J. (1997). Guide to assessing psychosocial yellow flags in acute low back pain: risk factors for long-term disability and work loss. Wellington: Accident Rehabilitation \& Compensation Insurance Corporation of New Zealand and the National Health Committee

Kosmas, I., Marmara, H., \& Stergioulas, A. (2009). Organization of traumatic injuries of women trained in municipal sports programs. Organization of sport, 7, 30-38.

Kriska, A.M., \& Caspersen, C.J. (1997). Introduction to a collection of physical activity questionnaires. Medicine \& Science in Sports \& Exercise, 29(6), 5-9. doi: 10.1097/00005768-199706001-00003

Lallukka, T., Viikari-Juntura, E., Viikari, J., Kähönen, M., Lehtimäki, T., Raitakari, O., \& Solovieva, S. (2017). Early work-related physical exposures and low back pain in midlife: the Cardiovascular Risk in Young Finns Study. Occupational and Environmental Medicine, 74(3), 163-168. doi: 10.1136/ oemed-2016-103727

Le Borgne, M., Boudoukha, A. H., Petit, A., \& Roquelaure, Y. (2017). Chronic low back pain and the transdiagnostic process: How do cognitive and emotional dysregulations contribute to the intensity of risk factors and pain? Scandinavian journal of pain, 17(1), 309-315. doi: 10.1016/j. sjpain.2017.08.008

Leboeuf-Yde, C., Kyvik, K. O., \& Bruun, N. H. (1998). Low Back Pain and Lifestyle: Part I: Smoking. Information From a Population-based Sample of 29,424 Twins. Spine, 23(20), 2207-2213.

Liira, J.P., Shannon, H.S., Chambers, L.W., \& Haines, T.A. (1996). Long-term back problems and physical work exposures in the 1990 Ontario Health Survey. American Journal of Public Health, 86(3), 382-387. doi: 10.2105/ AJPH.86.3.382.

Maniadakis, N., \& Gray, A. (2000). The economic burden of back pain in the UK. Pain, 84(1), 95-103. doi: 10.1016/S0304-3959(99)00187-6

Marmara, E.A., Papacharalambous, X.N., Kouloulias, V.E., Maridaki, D.M., \& Baltopoulos, J.P. (2011). Physical activity and mammographic parenchymal patterns among Greek postmenopausal women. Maturitas, 69(1), 74-80. doi: 10.1016/j.maturitas.2011.02.003

Miller, J. (2014, February 25). Is back, neck and muscle pain hurting the UK economy? Retrieved from BBC website: http://www.bbc.co.uk/news/ business-26338889

Mimic, J., Vukicevic, V., \& Vujacic, N. (2019). Comparative analysis of certain morphological characteristics of top tennis players in different periods. Journal of Anthropology of Sport and Physical Education, 3(2), 35-41. doi: 10.26773/jaspe.190407

Mortimer, M., Pernold, G., \& Wiktorin, C. (2006). Low back pain in a general population. Natural course and influence of physical exercise-a 5-year follow-up of the Musculoskeletal Intervention Center-Norrtälje Study. Spine, 31(26), 3045-3051. doi: 10.1097/01.brs.0000250324.03210.3f

Mortimer, M., Wiktorin, C., Pernold, G., Svensson, H., Vingård, E., \& Music-Norrtälje study group. (2001). Sports activities, body weight and smoking in relation to low-back pain: a population-based case-referent study. Scandinavian journal of medicine \& science in sports, 11(3), 178-184. doi: 10.1046/j.1524-4725.2001.110308.x 
Nachemson, A. (1991). Back pain, etiology, diagnostics, and treatment. Stockholm: Swedish Council on Technology Assessment in Health Care.

Ostgaard, H.C., Andersson, G.B.J., \& Karlsson, K. (1991). Prevalence of Back Pain in Pregnancy. Spine, 16(5), 549-552. doi: 10.1097/00007632199105000-00011

Shiri, R., Karppinen, J., Leino-Arjas, P., Solovieva, S., \& Viikari-Juntura, E. (2010). The Association between Smoking and Low Back Pain: A Meta-analysis. The American Journal of Medicine, 123(1), 87.e7-87.e35. doi: 10.1016/j.amjmed.2009.05.028

Smedley, J., Egger, P., Cooper, C., \& Coggon, D. (1995). Manual handling activities and risk of low back pain in nurses. Occupational and environmental medicine, 52(3), 160-163. doi: 10.1136/oem.52.3.160

Spais, G. (2007). Introduction to the management of technological innovations. Athens: Kritiki publications.
Spyropoulos, P., Papathanasiou, G., Georgoudis, G., Chronopoulos, E., Kou tis, H., \& Koumoutsou, F. (2007). Prevalence of low back pain in Greek public office workers. Pain physician, 10(5), 651-660.

Thomas, N., \& Nelson, J. (2003). Research Methods in Physical Activity [in Greek]. Athens: Paschalidis.

Van Tulder, M.W., Koes, B.W., \& Bouter, L.M. (1995). A cost-of-illness study of back pain in The Netherlands. Pain, 62(2), 233-240. doi: 10.1016/03043959(94)00272-G

Waddell, G., Feder, G., Mclntosh, A., Lewis, M., \& Hutchinson, A. (1998). (1996) Low Back Pain Evidence Review London: Royal College of General Practitioners. Journal of Manual \& Manipulative Therapy, 6(3), 151-153. doi: 10.1179/jmt.1998.6.3.151 